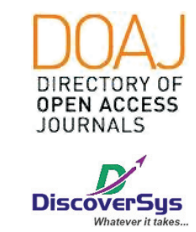

Published by DiscoverSys

\section{The short-term disadvantageous of tension-suture and spica cast application in exstrophy-epispadias complex reconstruction: a case report}

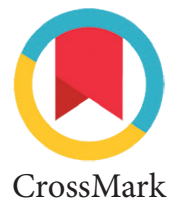

\author{
Ida Bagus Putra Pramana, ${ }^{1 *}$ Anak Agung Gde Oka, ${ }^{2}$ Gede Wirya Kusuma Duarsa, ${ }^{2}$ Kadek Budi \\ Santosa, ${ }^{2}$ I Wayan Yudiana, ${ }^{2}$ Pande Made Wisnu Tirtayasa ${ }^{2}$
}

'Urology Surgeon, Faculty of Medicine, Universitas Udayana, Universitas Udayana General Hospital, Bali Indonesia ${ }^{2}$ Department of Urology Surgery, Faculty of Medicine, Universitas Udayana, Sanglah General Hospital, Bali, Indonesia

*Correspondence to: Ida Bagus Putra Pramana; Urology Surgeon, Faculty of Medicine, Universitas Udayana, Universitas Udayana General Hospital, Bali Indonesia;

bagusputra@unud.ac.id

Received: 2019-09-04

Accepted: 2019-11-08

Published: 2019-12-01

\title{
Abstract
}

Background: Exstrophy-epispadias complex (EEC) represents a spectrum of genitourinary malformations and associated with another congenital anomaly. EEC is a rare congenital disability. EEC affects the genitourinary system, anterior abdominal wall, musculoskeletal system, spine and anus. The surgical outcome has a lot of potential complications in patient with EEC. The decision to first approach is important for the next step. Herein, we reported a case of EEC with several anomalies.

Case Description: A new-born male was born with section cesarean at 38 weeks of gestation from 34-year-old mother, and this is from the second pregnancy. The weight was 3300 grams, and the height was 48 centimetres. There was an abdominal wall defect with an exposed evaginated bladder plate with urine draining from the defect. A complete dorsally opened urethral plate was seen from the bladder neck down to the glandular grove. The patient was diagnosed with Exstrophy-epispadias complex (EEC). A 2 stage repair was conducted in this patient. After 10 days post-operation, the wound became dehiscence and got sepsis postoperatively as well as lead to die in the day 20.

Conclusion: Wound dehiscence following reconstruction is very critical inpatient with EEC. Tension suture and spica cast application can be disadvantageous inpatient with EEC.

Keywords: exstrophy epispadias complex, congenital malformation, pediatric, reconstructive.

Cite This Article: Pramana, I.B.P., Oka, A.A.G., Duarsa, G.W.K., Santosa, K.B., Yudiana, I.W., Tirtayasa, P.M.W. 2019. The short-term disadvantageous of tension-suture and spica cast application in exstrophy-epispadias complex reconstruction: a case report. Intisari Sains Medis 10(3): 750-752. DOl: $10.15562 /$ ism.v10i3.605

\section{INTRODUCTION}

Exstrophy-epispadias complex (EEC) is a congenital anomaly of the genitourinary system with congenital malformations ranging from isolated epispadias to classical bladder exstrophy, and cloacal exstrophy is the most severe presentation. ${ }^{1}$ Besides, EEC also involved musculoskeletal system, pelvic floor musculature, and bony pelvis anomalies. ${ }^{1}$ Bladder exstrophy is a rare congenital malformation, with an estimated incidence of approximately 1 per 50,000 live births and affecting males approximately twice as often as females. ${ }^{2}$ EEC is caused by a derangement in mesodermal layers fusion during the first weeks of fetal life. ${ }^{3}$ At the end third week of gestation, intermediate layer of mesoderm starts to invaginate to give origin to the urogenital system, while the lateral plate mesoderm will contribute to forming the primitive gut tube. $^{3}$ A disruption in this interaction is related to a cloacal membrane overgrowth and is prevent medial migration of mesenchymal tissue. EEC can be diagnosed prenatally with fetal transabdominal ultrasound (US) between the $15^{\text {th }}$ and $32^{\text {nd }}$ weeks of pregnancy. ${ }^{2,3}$

Several studies have been concerned about the surgical treatment need to be provided among patients with EEC. A surgical closure approach on bladder exstrophy in the neonatal period is the current primary method of care for most infants. ${ }^{4}$ A majority of these patients were known undergone either complete primary closure or modern staged reconstruction. ${ }^{4}$ The success of initial bladder exstrophy closure is essential for the development of adequate bladder capacity and future urinary continence. ${ }^{4}$ In order to reach this goal, a tension-suture and spica cast application techniques have been mentioned as one of appropriate interventions among EEC patients. ${ }^{5,6}$

A tension-suture method has been preferred for patients who undergone abdominoplasty procedures. ${ }^{7}$ This suture-technique is known can reduce the local complications, including hematoma and seroma formation, flap necrosis, and hypertrophic scars in this procedure. ${ }^{7}$ This technique also could be implemented on EEC patients. Besides, a conservative approach by increasing the immobility post-operatively is required to reduce the complications. Spica-cast application has been well known for its safety and efficacy for immobilization following initial bladder closure in classic bladder exstrophy. ${ }^{6}$ However, the short-term disadvantageous of 
tension-suture and spica cast application in exstrophy-epispadias complex reconstruction has not been well documented. Based on those mentioned above, this study aims to evaluate the case report in showing the pitfall following EEC operation.

\section{CASE REPORT}

A new-born male was born with section cesarean at 38 weeks of gestation from 34-year-old mother and this is from the second pregnancy. The weight was 3300 gram, and the height was 48 centimetres. Previously, the mother has had a spontaneous abortion on first pregnancy at 28 weeks' gestation with unknown aetiology.

The husband was 36-year-old - the new-born presented with a genitourinary defect and

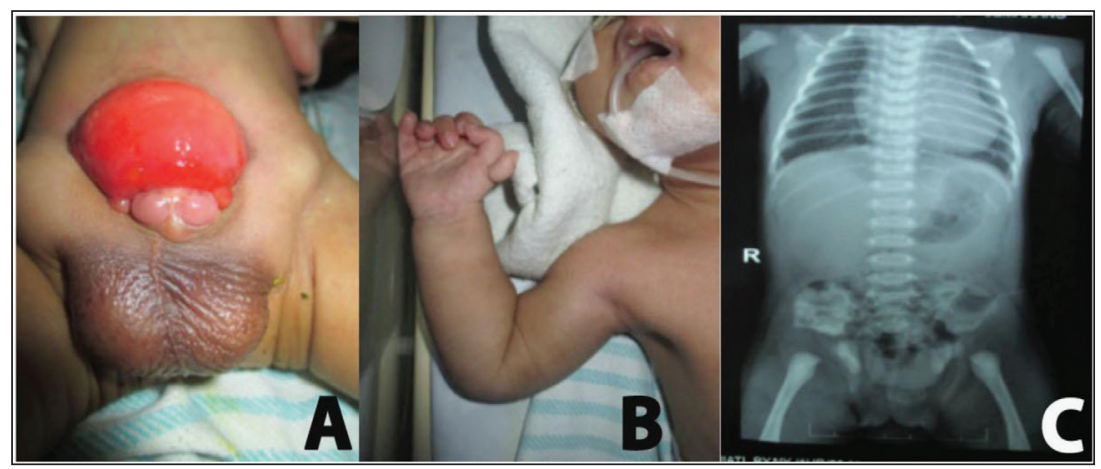

Figure 1 (A) Bladder exstrophy, normal scrotum with palpable testis on both side of the scrotum, and two corpus cavernosa. (B) Polydactyly on the right thumb. (C) Babygram Radiology showing separation of the pubic symphysis, external rotation of pelvic bone and increasing of intertriradiate distance.

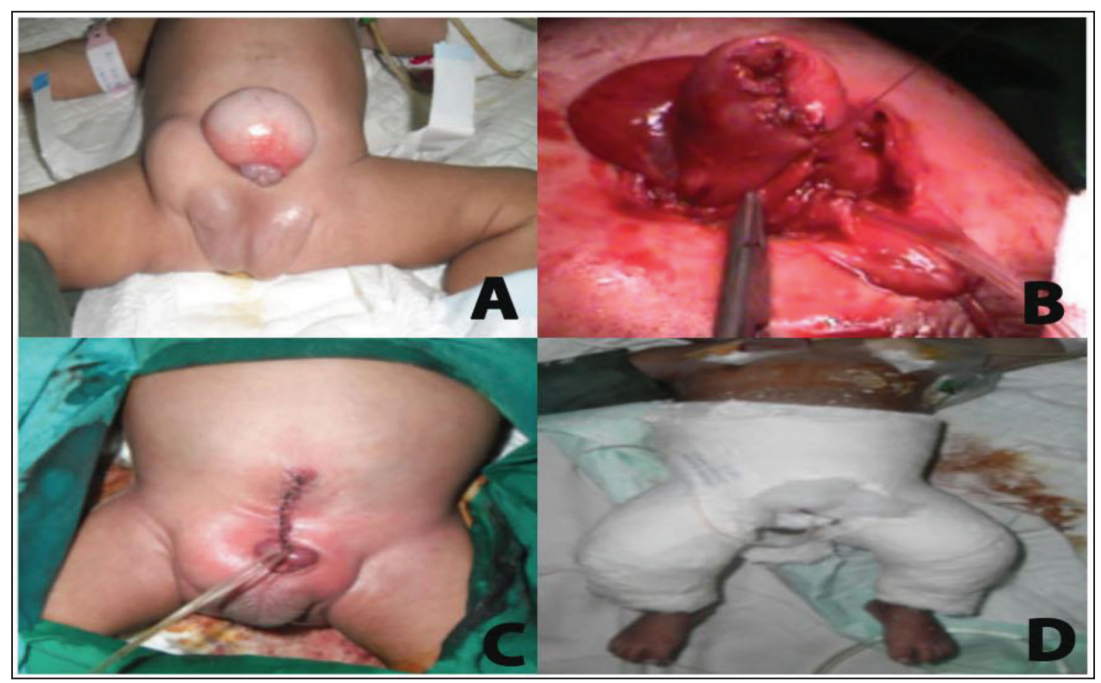

Figure 2 (A) Alteration of bladder mucosa with whitish coating due to delayed repair accompanied with right inguinal hernia. (B) The bladder was separated from abdominal wall and two-layered sutures were applied on bladder (C) Post reconstruction of bladder (D) spica-cast was applied by orthopaedic post-operation. polydactyly on right thumb (Figures $1 \mathrm{~A}$ and $1 \mathrm{~B}$ ). There was an abdominal wall defect with an exposed evaginated bladder plate with urine draining from the defect, a complete dorsally opened urethral plate was seen from the bladder neck down to the glandular grove, both corpora cavernosa were clearly visible beneath and alongside the urethral plate, the scrotum was normal with descended testis on both side. There was no associated anorectal malformation (ARM), the anus was present, baby had meconium when he was born and was able to defecate. Echocardiography examination found ASD and PDA. The PDA defect closed spontaneously after 46 days and right after that, we decided to perform two stages reconstruction for this patient. We also found indirect right inguinal hernia. These genitourinary anomalies were consistent with EEC. Chromosome examination was held and revealed 46XY. Haematology examinations including full blood count, urea, creatinine and serum electrolytes were performed and the results were normal. Babygram radiology showed separation of pubic symphysis more than $4 \mathrm{~cm}$ and external rotation of anterior segment pelvic bone more than $18^{\circ}$. Intertriradiate distance also increases (Figure 1C). Delayed closure in this patient leads to further inflammatory or mechanical alterations with signs of mucosal inflammation such as a whitish coating (Figure 2A). We were planning to perform 2 stage repairs in this patient. The first stage was osteotomy by orthopaedics surgeon and bladder reconstruction (Figure 2B, 2C and 2D). We performed bladder neck and epispadias reconstruction on the second stage. However, after 10 days post-operation, the wound became dehiscence (Figure 3) and patient has sepsis due to the dehiscence. Eventually, at 20 days, a post-operation patient died because of sepsis condition.

\section{DISCUSSION}

In most EEC cases, the bladder and abdominal wall should be closed soon after birth. The standard-staged repair, primary closure of the bladder without osteotomy, and genital reconstruction must attempted in the first 72 hours of life to performed reconstruction. ${ }^{8}$ At birth, hamartomatous polyps were seen on the exstrophy bladder surface in about $50 \%$ of the cases. ${ }^{9}$ These polyps have been interpreted as reactive, potential pre-malignant environmental changes. ${ }^{9}$ Closure of the bladder within the first few hours of life is widely recommended in-patient with exstrophy bladder. In this case, we performed bladder reconstruction after the PDA closed spontaneously on 46 days.

Indirect inguinal hernias inpatient with EEC is due to a persistent processus vaginalis, large 


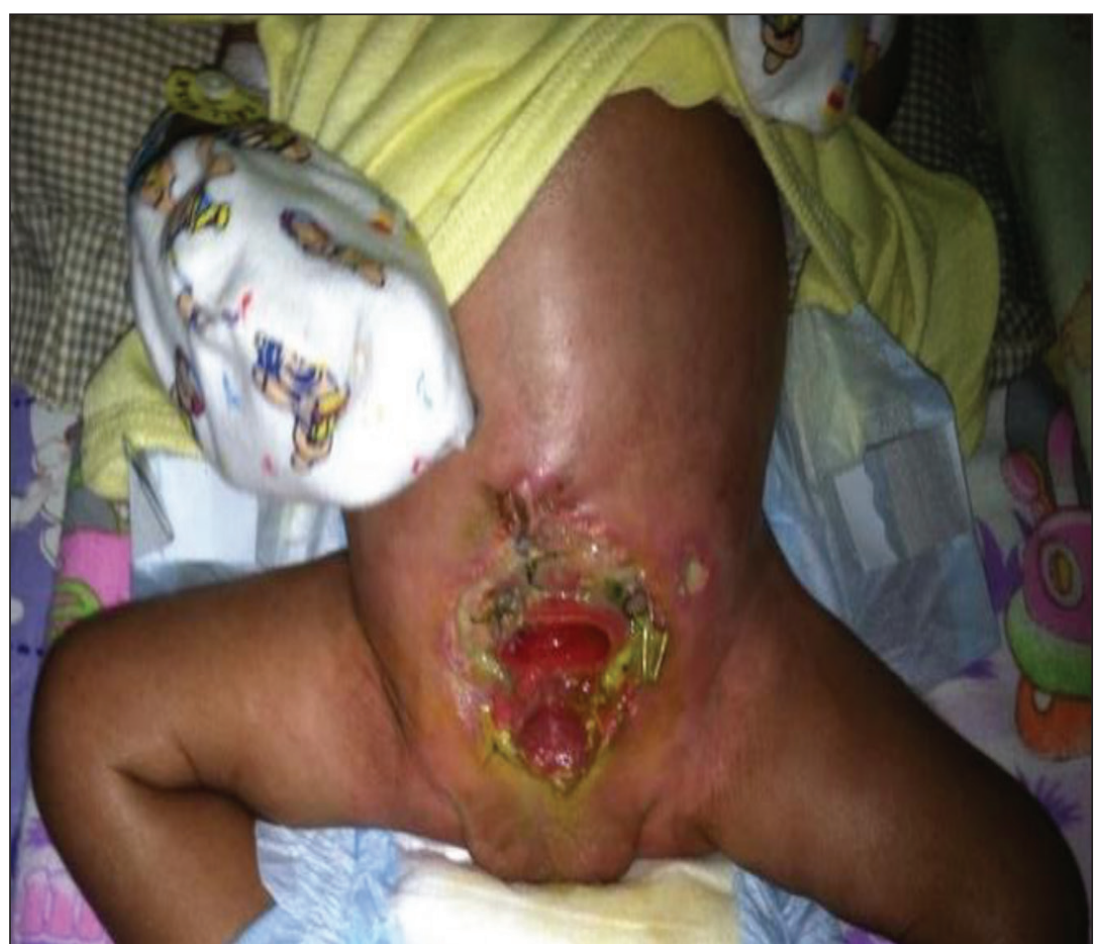

Figure 3 Wound dehiscence in 10 days post-operative

inguinal rings, and the relatively straight direction of the inguinal canal..$^{10}$ In a review of 181 children with bladder exstrophy, it was reported that inguinal hernia was found in $81.8 \%$ boys and $10.5 \%$ girls. ${ }^{11}$ EEC patients have a mean pubic diastasis of 4.8 centimetres, external rotation of both the anterior and posterior segments of the pelvis, increased distance between the triradiate cartilage. ${ }^{12}$ Skeletal and limb anomalies such as clubfoot deformities, absence of feet, tibial or fibular deformities, and hip dislocations were commonly seen. ${ }^{8}$ A retrospective study showed that use of spica casting and "mummy wrapping" were associated with lower overall success of the primary closure and higher rate of skin breakdown compared to modified Bryant traction and Buck's traction. ${ }^{13}$ EEC patients sometimes have rectal stenosis, omphalocele, imperforate anus, and rectal prolapse. However, we did not find those anomalies in this patient. Both single and two-staged repairs are suitable procedures to repair EEC. Wound dehiscence, bladder outlet obstruction, bladder prolapse and vesicocutaneous fistula formation that require re-reconstruction have been reported with both techniques. ${ }^{14}$

\section{CONCLUSION}

Based on our analysis, the cause of surgery failure is due to tension suture and the use of Spica cast for immobilization. Spica-cast application post-operation made a difficulty for doctor to evaluate operation's wound.

\section{CONFLICT OF INTEREST}

There is no competing interest regarding the manuscript

\section{FUNDING}

This research did not receive any specific grant from funding agencies. There is no conflict of interest.

\section{AUTHOR CONTRIBUTION}

All of the authors are equally contributed to the case report from data gathering until reporting the outcome of study

\section{REFERENCES}

1. Ebert AK, Reutter H, Ludwig M, Rösch WH. The exstrophy-epispadias complex. Orphanet J Rare Dis. 2009;4:23.

2. Nelson CP, Dunn RL, Wei JT. Contemporary epidemiology of bladder exstrophy in the United States. J Urol. 2005;173(5):1728-1731

3. Mahfuz I, Darling T, Wilkins S, White S, Cheng W. New insights into the pathogenesis of bladder exstrophy-epispadias complex. J Pediatr Urol. 2013 Dec;9(6 Pt B):996-1005.

4. Oesterling JE, Jeffs RD. The importance of a successful initial bladder closure in the surgical management of classical bladder exstrophy: analysis of 144 patients treated at the Johns Hopkins Hospital between 1975 and 1985. J Urol 1987; 137:258e62

5. Inouye BM, Tourchi A, Di Carlo HN, Young EE, Gearhart JP. Modern management of the exstrophy-epispadias complex. Surg Res Pract. 2014;2014:587064.

6. Arlen AM, Cooper CS, Morcuende J, Austin JC. Safety and efficacy of spica casts for immobilization following initial bladder closure in classic bladder exstrophy. J Pediatr Urol. 2011;7(4):456-9.

7. Pollock H, Pollock T. Progressive tension sutures: a technique to reduce local complications in abdominoplasty. Plast Reconstr Surg. 2000;105(7):2583-6

8. Dodson JL, Surer I, Baker LA, Jeffs RD, Gearhart JP. The newborn exstrophy bladder inadequate for primary closure: evaluation, management and outcome. J Urol. 2001;165(5):1656-9.

9. Jelsig AM, Qvist N, Brusgaard K, Nielsen CB, Hansen TP, Ousager LB. Hamartomatous polyposis syndromes: a review. Orphanet J Rare Dis. 2014;9:101.

10. Stringer MD, Duffy PG, Ransley PG. Inguinal hernias associated with bladder exstrophy. Br J Urol. 1994;73(3):308-9.

11. Connolly JA, Peppas DS, Jeffs RD, Gearhart JP. Prevalence and repair of inguinal hernias in children with bladder exstrophy. J Urol. 1995;154(5):1900-1.

12. Stec AA. Embryology and bony and pelvic floor anatomy in the bladder exstrophy-epispadias complex. Semin Pediatr Surg. 2011;20(2):66-70

13. Shnorhavorian M, Song K, Zamilpa I, Wiater B, Mitchell MM, Grady RW. Spica casting compared to Bryant's traction after complete primary repair of exstrophy: safe and effective in a longitudinal cohort study. J Urol. 2010 Aug;184(2):669-73.

14. Meldrum KK, Baird AD, Gearhart JP. Pelvic and extremity immobilization after bladder exstrophy closure: complications and impact on success. Urology. 2003;62(6):1109-13.

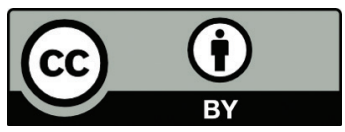

This work is licensed under a Creative Commons Attribution 